\title{
Autoria e propriedade - inflexões e perspectivas de uma relação em crise
}

\section{Authorship and property - inflections and perspectives of a relation in crisis}

\section{Beatriz Cintra Martins I}

Doutora em Ciências da Comunicação pela Escola de Comunicações e Artes da Universidade de São Paulo. Pesquisadora dos grupos de Novas Tecnologias, Cultura e Práticas Interativas e Inovação em Saúde, da Fundação Oswaldo Cruz, e Economias Colaborativas e Produção P2P no Brasil, do IBICT/UFRJ.

\section{Resumo}

As relaçôes entre autoria e propriedade estão em crise na atualidade, sob o impacto das novas dinâmicas autorais presentes nas redes de comunicação. Neste artigo, num primeiro momento, percorremos a história da autoria, pontuando suas inflexôes. Em seguida, apresentamos algumas licenças alternativas que têm sido criadas como um questionamento prático das restrições vigentes quanto à propriedade intelectual.

Palavras-Chave: Autoria; propriedade intelectual; licenças alternativas.

\begin{abstract}
Relations between authorship and property are currently in crisis under the impact of new authorial dynamics in communication networks. In this article, we first address the history of authorship, emphasizing its inflections. Next, we present some alternative licenses that have been created as a practical way of calling into question the prevailing intellectual property constraints.
\end{abstract}

Keywords: Authorship; intellectual property; alternative licenses. 


\section{Introdução}

Entre as mudanças trazidas pelo advento das redes eletrônicas de comunicação, a que diz respeito à questão autoral é uma das mais significativas. A noção de autoria, anteriormente atribuída a um indivíduo determinado, em geral reconhecido por seus méritos ou credenciais, se encontra deslocada na atualidade sob o impacto das tecnologias digitais. Em seu lugar, surge o autor em rede, de natureza difusa e distribuída, composto da interação entre uma multidão de atores que produzem uma obra de forma compartilhada. Este é o caso, por exemplo, da enciclopédia colaborativa Wikipédia, com 25 milhóes de artigos escritos em 285 idiomas por milhóes de colaboradores ${ }^{1}$, não necessariamente especialistas e muitos deles anônimos.

Essa inflexão nos processos autorais tem desafiado os parâmetros vigentes de gestáo de direitos de bens intelectuais e provocado um intenso debate na sociedade sobre como lidar com a nova dinâmica da produção em rede. Um das dificuldades em se avançar nessa discussão é dar conta de analisar transformaçóes culturais tão recentes sem cair numa abordagem de estranhamento e resistência por sua diferença ou, ao contrário, de deslumbramento por sua novidade. Um dos caminhos para se evitar essas tendências é buscar a perspectiva histórica, que oferece parâmetros que podem dar mais clareza à reflexão sobre as relaçóes entre autoria e propriedade.

Neste artigo, como contribuição para o aprofundamento desse debate, traremos alguns referenciais históricos que podem ajudar na compreensão das premissas da noção de autoria proprietária e na percepção da necessidade de sua revisão. Em um primeiro momento, iremos percorrer brevemente a história da autoria a fim de explorar as diferentes constituiçóes e dinâmicas dos processos autorais em épocas diversas. Em seguida, nos deteremos na análise da conjuntura que possibilitou o surgimento da figura do autor individual e do gênio criador, e que deu base para a consolidaçáo da ideia de propriedade intelectual que vigora ainda hoje. Por último, abordaremos os novos modelos autorais que têm lugar nas redes de comunicação e sua incompatibilidade com os parâmetros atuais que regem o direito autoral. Como complemento, apresentaremos algumas licenças alternativas para a gestão de bens intelectuais que têm sido criadas como um questionamento prático às restriçốes legais vigentes.

\section{A historicidade da autoria}

O ponto de partida para construir nossa reflexão é resgatar o caráter histórico da noção de autoria a fim de desnaturalizar certa acepção que se tem como universal, a do indivíduo autor, que embasa o marco regulatório sobre propriedade intelectual na atualidade. Para isso recorremos inicialmente ao pensamento de Michel Foucault, que em sua célebre palestra " $O$ que é um autor?", na Société Française de Philosophie, em 1969, aponta para a historicidade das práticas autorais, lembrando que nem sempre os textos tiveram uma assinatura: 
Os textos, os livros, os discursos começaram efetivamente a ter autores (outros que não personagens míticas ou figuras sacralizadas e sacralizantes) na medida em que o autor se tornou passível de ser punido, isto é, na medida em que os discursos se tornaram transgressores (FOUCAULT, 2006, p. 47).

A relação entre a atribuição e o regime de propriedade é ressaltada por Foucault, que identifica o período entre o final do século XVIII e o início do XIX como o momento em que se instauraram tanto as regras estritas sobre o direito do autor, quanto a aura transgressora da literatura, como dois polos de um sistema que incluía reconhecimento e risco. No entanto, destaca o filósofo, houve épocas em que textos, hoje considerados literários, circulavam na cultura sem necessidade de um nome de autor que validasse sua existência. Sua própria duração na cultura, a maneira como persistia através de geraçóes, era já uma confirmação de seu valor.

De fato, podemos observar que houve significativa variação nos processos autorais em diferentes épocas. $\mathrm{Na}$ Antiguidade, por exemplo, as lendas e os contos populares eram transmitidos, em grande parte, por via oral. Os poemas épicos eram declamados pelos bardos, que podiam improvisar e incluir seus próprios versos em sua performance. Seus acréscimos, no entanto, não eram marcados por uma assinatura. Poderiam posteriormente ser incorporados em outras apresentações, sem referência a uma atribuição. A criação poética de então não tinha um caráter individual. Ao contrário, era entendida como uma inspiração "soprada" pelas musas, entidades míticas que corporificavam a consciência da tradição coletiva. Uma prática, portanto, de natureza transcendental, anônima, e tratada como uma criação comum (FERNANDES, 2003).

No período medieval, também era comum o anonimato. Segundo Bennett (2005), interessava menos ao público leitor o nome do autor do que aquilo que ele revelava, o conteúdo de sua escrita. Isso porque o texto não tinha a conotação de uma expressão pessoal subjetiva, mas era muito mais uma tentativa de interpretação de uma verdade divina. Burke (1995) vai endossar essa análise ao afirmar que a escritura na Idade Média fazia parte de um contexto cultural no qual Deus era a fonte da inspiração suprema para todas as obras, o seu verdadeiro autor. $\mathrm{O}$ artista ou escritor era considerado um transmissor da criação divina, não cabendo a ele, portanto, um mérito autoral particular por suas realizaçóes. Para Burke, esse modelo da inspiração divina, acima da autoria humana, não se limitava aos textos bíblicos, mas abarcava toda a produção intelectual da época, que seria sempre a revelação pública de um saber transcendental e nunca uma intuição de caráter privado.

Eram usuais, então, as publicaçôes manuscritas com comentários nas marginálias, que eram lidas em voz alta e em público, quando podiam receber novos acréscimos. Esse modo de escrita, conhecido como método 
escolástico, consistia em um exercício de hermenêutica da comunidade religiosa sobre os textos bíblicos, com uma dinâmica mais coletiva do que individual. Vale mencionar que essa produçáo textual era validada por uma entidade conhecida como auctoritas, formada por clérigos que possuíam o poder de chancelar seu valor como material digno de leitura.

Já no final da Idade Média, há registro de uma prática de escrita que, pode-se afirmar, ia além da tarefa de interpretação obediente ao cânone para se constituir mesmo em um ato de leitura e escrita criativa. Este é o caso da obra "The Canterbury Tales", atribuída ao escritor inglês Geoffrey Chaucer, do século XIV, que teve várias versôes produzidas por leitores, com cortes e acréscimos, num processo de autoria fluido. Para Liang (2005), mais do que um caso isolado, este era o padrão da época, no qual os textos eram tidos como mutáveis, passíveis de ediçôes e adaptações, e os leitores eram livres para interferir no manuscrito com suas anotaçóes que se mesclavam com o texto original, formando outra obra. Cabe ainda registrar que o próprio Chaucer se declarava um mero repetidor de estórias contadas por outros.

Tanto no período antigo quanto no medieval, a falta de relevância da atribuição de autoria estava relacionada ao entendimento de que as obras eram parte do patrimônio comum. No entanto, com o advento da Modernidade, época da valorização do sujeito como protagonista da vida social, a concepção de processo criativo e, consequentemente, a visão a respeito dos direitos sobre a produção intelectual mudaram radicalmente.

\section{O fortalecimento do indivíduo autor na Modernidade}

Com a chegada da Modernidade e a emergência do projeto do sujeito autônomo, a figura do autor individual se fortalece. O ser humano, racional e consciente, passou a ocupar a centralidade do universo, a ser ele próprio o agente do conhecimento, acima do dogma religioso e das crenças. Paralelamente, esse foi também o período da invençáo da imprensa e de significativas mudanças nas práticas de escrita e leitura. O texto se tornou mais fechado em um duplo sentido: por um lado, passa a ter um autor individual identificado; por outro, não estava aberto para intervençóes ou comentários. Ao mesmo tempo, a prática da leitura também se individualizou: as leituras públicas da era medieval foram pouco a pouco sendo substituídas pela leitura silenciosa e solitária.

A circulação de livros, por outro lado, ganhou uma dimensão inédita. No lugar do antigo manuscrito - uma única cópia podia demorar até dois meses e meio para ser concluída -, os exemplares impressos eram múltiplos, em tiragens de 500 a 1000 exemplares e, com isto, chegavam a um número cada vez maior de leitores. A economia alcançou outro patamar de complexidade, com o grande desenvolvimento do comércio, desdobrando-se em uma sofisticação dos instrumentos legais e políticos da organização social. Nesse ambiente, cresceram também os investimentos no emergente negócio do livro, visto então como mais uma commodity, e a figura do editor-livreiro, responsável pelo tratamento do texto, sua impressão e distribuição, conquistou destaque. Como 
o setor ganhou importância econômica, era preciso estabelecer regras claras sobre os direitos de impressão a fim de proteger o investimento feito pelos editores na compra de manuscritos e garantir a conquista de novos mercados.

Desde o século XVI havia o sistema conhecido como privilégio, que funcionava com uma espécie de concessão dada pela monarquia, para garantir aos impressores a exclusividade de publicação de determinados livros e, assim, assegurar a realização de lucro sobre seus investimentos. Vale lembrar que naquela época o editor comprava o original sem saber ao certo se a obra cairia no gosto do público ou se representaria prejuízo. Por outro lado, era comum a realização de cópias não autorizadas dos livros mais vendidos por outros editores que queriam se aproveitar da popularidade das publicaçôes sem, no entanto, ter se exposto ao risco do empreendimento. Esse sistema, no entanto, era limitado a territórios específicos, municípios ou estados, o que funcionou bem enquanto a demanda por livros também era restrita. Mas, na medida em que o mercado editorial cresceu e se expandiu geograficamente, esse modelo se mostrou ineficaz. A Alemanha, por exemplo, tinha cerca de 300 estados independentes no século XVIII: para garantir a exclusividade de publicação, seria preciso obter o privilégio em cada um deles (WOODMANSEE, 1994).

A fim de atender à nova dinâmica da economia do livro e aos interesses dos livreiros, importantes comerciantes da época, foi promulgada em 1710, mais de 250 anos após a invenção da imprensa, a primeira legislação referente ao direito autoral, o Copyright Act, pela Rainha Anne da Inglaterra. Nessa época, embora alguns autores fossem remunerados pelos editores, os honorários que recebiam eram bem modestos e náo correspondiam à retribuiçáo por seu trabalho nem garantiam sua subsistência. Os escritores ainda não eram reconhecidos como agentes produtores dignos de remuneração, o que só vai ocorrer gradativamente, durante o século XVIII, com o crescimento do interesse pela leitura, quando começaram a reivindicar o direito de viver da venda de seu trabalho intelectual.

Uma contribuição importante para a consolidação da noção de autoria como um atributo individual foi dada pelo movimento do Romantismo, nos séculos XVIII e XIX. De acordo com Woodmansee (1994), os escritores desse período minimizaram o valor da habilidade técnica dos artesãos e deslocaram o elemento da inspiração, antes vinda das musas ou de Deus, para a interioridade do autor. O trabalho dos homens de ofício tradicionais, antes valorizados por sua capacidade de reproduzir a beleza divina, passou a ser visto como menor, sem distinçáo, uma mera reprodução de clichês. Por outro lado, o processo autoral passou a ser entendido como algo gerado a partir de uma profundidade subjetiva, em uma expressão única e original. Essa nova compreensão, por sua vez, deu base para o surgimento da figura do gênio criador. Nesse contexto, o trabalho intectual alcançou outro estatuto, ou seja, a partir de então se tornou digno de ser remunerado como uma contribuição relevante 
à sociedade. Não mais de um artesão ou de um imitador, lidando com conteúdos culturais comuns ou transcendentais, mas de um criador que merece ser financeiramente recompensado por seu talento único e pela originalidade de sua produção. Foram aí lançados os fundamentos do direito autoral tal como o conhecemos (WOODMANSEE, 1994).

Um dos pensadores que influenciaram a mentalidade na época e contribuíram para esse novo entendimento da figura do autor foi Johann Gottlieb Fichte, com destaque para seu texto "Proof of the Illegality of Reprinting: A Rationale and a Parable", no qual defende que cada escritor tem uma maneira pessoal e única de estruturar seus pensamentos, de dar forma às suas ideias e de conectá-las. Condição que, argumenta, lhe confere o direito de autor, tanto do ponto de vista moral, como o criador de sua obra, quanto do material, como o detentor de sua propriedade:

[...] cada indivíduo tem seu próprio processo de pensamento, a sua própria maneira de formar conceitos e conectá-los. [...] Tudo o que nós pensamos, devemos pensar de forma análoga a nossos outros hábitos de pensamento, e somente retrabalhando novos pensamentos, depois de compará-los com nosso processo habitual de pensamento, é que os fazemos nossos [...] Assim, cada escritor deve dar a seus pensamentos uma certa forma, e ele não pode dar-lhes outra forma senão a sua, porque ele não tem outra. Mas ele também não pode querer ceder esta forma ao tornar seus pensamentos públicos, porque ninguém pode se apropriar de seus pensamentos sem, contudo, alterar a sua forma. Esta, assim, permanece para sempre sua propriedade exclusiva. (FICHTE apud WOODMANSEE, 1994, p. 51-52, grifos do autor). ${ }^{2}$

O conceito-chave apresentado por Fichte - de que cada indivíduo tem uma forma de pensamento exclusiva - fundamentou as leis de direito autoral promulgadas nas décadas seguintes, que passaram a reconhecer a legitimidade da reivindicaçáo de direitos exclusivos do autor sobre obra original de sua criação intelectual. O escritor a partir de então ganha outro estatuto, e direitos de propriedade, em reconhecimento à singularidade de seu pensamento (WOODMANSEE, 1994).

De todo modo, a concepção do autor individual e autônomo começou a ser questionada ainda no século XIX. Um dos precursores da crítica à concepção Romântica de gênio criador foi Mallarmé, um dos maiores poetas da época, por propor a separação, mais do que a união, entre o autor e a obra. Mais ainda, Mallarmé atribui a origem da criação poética não à imaginação ou ao inconsciente de um autor, mas sim à palavra, compreendida por ele como puro logos. Suas alusóes à intertextualidade, ao desaparecimento do autor e ao poder generativo da linguagem irão inspirar a teoria francesa da écriture no século XX. Esta influência fica muita clara nas palavras de Barthes (2004).

Na França, Mallarmé, sem dúvida o primeiro, viu e previu em toda a sua amplitude a necessidade de colocar a própria linguagem no lugar daquele que era até então considerado seu proprietário, para ele, como para nós, é a linguagem que fala, não o autor; escrever é, através de uma impessoalidade prévia [...] atingir esse ponto em que só a linguagem age, "performa", e não 
“eu” [...] (BARTHES, 2004, p. 59).

Barthes foi um dos principais críticos a desconstruir a figura do autor romântico, ao transferir para a linguagem a referência primeira da criação e ao afirmar a escritura como um espaço de múltiplas dimensôes e significados, sem nunca possuir um sentido último que de alguma forma determine de antemão o caminho estético a ser percorrido. E foi além, ao concluir que o lugar capaz de absorver toda a multiplicidade contida em uma escritura, náo é mais o do autor, mas o do leitor. A obra, neste sentido, só alcança sua plenitude na leitura, no desvendamento de seus sentidos pelo leitor. E para que este polo possa florescer é preciso que o outro decresça, ou seja, é preciso decretar a morte do autor como aquele que detém o monopólio do processo da criaçáo.

\section{Modelos autorais em rede}

Apesar de todo o questionamento a respeito da questáo autoral e da natureza do processo criativo durante o século XX, por pensadores como Barthes e Foucault, ainda prevalece na atualidade a concepção de autoria como aquela do Romantismo: a de autor como gênio criador. Essa noção está presente não só no senso comum, mas também, o que é mais significativo, embasa ainda as normas através das quais nos relacionamos com os bens intelectuais em nossa sociedade. No entanto, novas práticas autorais estimuladas pelo advento das redes eletrônicas de comunicação vêm abalando o entendimento da autoria como algo de caráter individual e, consequentemente, desestabilizando a concepção de propriedade intelectual e demandando sua revisão.

Não teremos espaço aqui para esmiuçar as características de diferentes modelos autorais presentes na rede, mas podemos mencionar brevemente algumas de suas características. Nos projetos colaborativos, como a Wikipédia que citamos na introdução, não é mais possível pensar o processo criativo como resultado de uma inspiração subjetiva ou a concepção de uma ideia como fruto da elaboração original de uma mente. Ao contrário, são obras produzidas de forma interativa e transindividual, nas quais vários atores contribuem com diferentes intervençóes que compóem um todo, como um produto coletivo. Mais ainda, muitas vezes, não existe a noção de conclusão da obra. O trabalho permanece em aberto, ad infinitum, para novas ediçốes que podem vir a modificá-lo de forma significativa, inclusive retirando algumas partes e introduzindo outras. Além disso, a questão de atribuição também é bastante difusa: na enciclopédia colaborativa, por exemplo, pode haver o registro de autoria, mas boa parte das contribuiçôes é de caráter anônimo.

O remix, outro modelo autoral típico das redes de comunicação, consiste na produção de obras a partir da recombinação de conteúdos culturais já existentes, como partes de textos e imagens de outras produçóes. Esse modelo questiona a atual regulaçáo sobre propriedade intelectual de forma ainda mais radical. Defende-se a ideia de que a cultura é desde sempre um bem a ser partilhado e que toda a obra cultural se apropria de outras que a precederam, fazendo parte de uma tradição comum compartilhada e não proprietária. Vale pontuar que a prática de apropriação é anterior à cultura digital, no entanto, adquire dimensão mais ampla pelas características propícias das redes de comunicaçáo, que permitem com muita facilidade a prática de copiar e colar trechos de outras obras. 
Os dois tipos de processo autoral em rede citados, o colaborativo e o remixado, pedem uma ampla e livre circulação de dados pela rede de forma a poderem ser compartilhados e recombinados, servindo de conteúdo para a produção de novas obras ou projetos. Como se vê, o conceito de propriedade intelectual baseado nas premissas dos séculos XVIII e XIX não se aplica mais para essas produçôes contemporâneas em rede, que representam outro entendimento do processo criativo e por isso demandam outras formas de gestão de direitos relativos aos bens intelectuais. Enquanto, no Brasil e em diversos países, os parlamentos discutem demoradamente propostas de adaptação da legislação aos novos tempos, artistas e ativistas saíram à frente e deram uma resposta prática ao problema, criando outros tipos de licenciamento com o objetivo de contemplar as novas dinâmicas criativas que pedem um fluxo mais livre da informação como condição de sua reprodução.

\section{Licenças alternativas}

O pioneiro em pensar uma licença alternativa para contemplar formas de produção colaborativa através das redes de comunicação foi Richard Stallman, fundador do Movimento Software Livre. A ideia central por trás desse movimento é defender o livre acesso aos códigos-fonte dos programas, em contraposição aos chamados programas proprietários desenvolvidos por empresas corporativas, que os mantêm fechados no modelo de segredo industrial. Stallman idealizou, em 1989, a General Public License (GPL), a fim de estabelecer direitos e garantias em outra direção: em lugar do copyright, o copyleft. Esta licença se baseia em quatro liberdades:

A liberdade de executar o programa, para qualquer propósito (liberdade no 0 )

A liberdade de estudar como o programa funciona, e adaptá-lo para as suas necessidades (liberdade no 1). Acesso ao código-fonte é um pré-requisito para esta liberdade.

A liberdade de redistribuir cópias de modo que você possa ajudar ao seu próximo (liberdade no 2).

A liberdade de aperfeiçoar o programa, e liberar os seus aperfeiçoamentos, de modo que toda a comunidade se beneficie (liberdade no 3 ). Acesso ao código-fonte é um pré-requisito para esta liberdade.

O importante a se destacar é que, dentro dessa lógica, o fluxo da informação deve ser livre a fim de que todos possam interagir amplamente com o programa. De acordo com a GPL, os programas devem ser distribuídos com o código-fonte aberto para que sejam passíveis de modificaçôes e aperfeiçoamentos. Porém estas derivaçôes obrigatoriamente devem manter as mesmas liberdades originais, isto é, devem ser licenciadas da mesma forma para que se impeça a sua apropriação por iniciativas proprietárias fechadas. Ou em outras palavras, a licença permite a criação de obras derivadas, mas impede a mudança no seu regime de distribuição. É interessante observar que a GPL desloca o foco do direito do autor, como o(s) indivíduo(s) criador(es) e detentor(es) de direitos restritivos sobre a obra, para enfatizar no melhor desempenho do programa como o objetivo maior a ser alcançado, em prol do qual os direitos proprietários devem ser relativizados. 
Ao definir a proibição de se mudar a licença em obras derivadas, a GPL assegura a constituição de um acervo de códigos-fonte como um patrimônio comum da comunidade de programadores, a partir do qual se pode avançar no desenvolvimento de novos programas ou outras funcionalidades. Dessa forma, portanto, essa licença preconiza a evolução do conhecimento como o valor mais alto, acima de direitos individuais exclusivos. Cabe mencionar ainda que, entre as determinaçóes deste licenciamento, está previsto o registro da atribuição de autoria de todos os que contribuíram para o desenvolvimento de um programa e de suas derivaçóes, resguardando, portanto, os direitos morais de todos os envolvimentos em sua produção.

A iniciativa da GPL tem inspirado a criação de outras licenças alternativas. A mais conhecida delas, sem dúvida, é a Creative Commons, idealizada por Lawrence Lessig, advogado e pesquisador de cibercultura. Sua primeira versão foi lançada em 2002, com o objetivo de oferecer um espectro de opçôes de proteção para obras culturais, como textos, música, filmes, imagens etc. No lugar do conceito de "Todos os direitos reservados", do Copyright, ou de "Nenhum direito reservado", do Domínio Público, a CC propóe a existência de alguns direitos reservados. A licença mantém o direito de autor, assim como os direitos conexos, mas pode autorizar a priori alguns direitos a mais, conforme a especificação escolhida pelo autor da obra.

Desse modo, é possível montar variaçôes da licença de acordo com os seguintes atributos: permissão de uso comercial ou não; permissão de transformação da obra ou não; e na segunda opção, é possível ainda permitir que as obras derivadas tenham licença diferente da obra original ou obrigá-las a manter a mesma licença. Além disso, existem também outras modalidades específicas, como as licenças: "Recombinação" ou "Sampling", "Naçóes em Desenvolvimento" e para software livre, chamada "CC-GNU-GPL". O propósito da licença CC seria adequar as produçôes intelectuais à dinâmica da Internet, permitindo circulação mais ampla e maximizando o potencial de compartilhamento e recombinação das obras, típicos da cultura digital.

A licença Creative Commons, no entanto, tem recebido críticas por resguardar o princípio de propriedade intelectual com a diretriz de "alguns direitos reservados", focando mais em garantir direitos a quem produz do que em estabelecer critérios com vistas à geração e à preservação do bem comum, como propóe a GPL ${ }^{3}$. Na verdade, esta licença tem uma inspiração liberal: seu objetivo é fornecer um leque de opçôes ao criador sobre como quer que sua obra circule. Em alguns casos, especialmente quando não obriga a manutenção da mesma licença, chega a permitir a apropriação privada de obras derivadas - ao contrário da licença GPL, que estabelece limites e liberdades para garantir que as produçóes derivadas permaneçam como um patrimônio comum. Talvez por isso mesmo, por sua flexibilidade e por não representar uma subversão ao modus operandi da produção corporativa proprietária, a CC tenha se tornado tão disseminada, com usos nas mais diversas áreas. 
Por outro lado, a licença GPL foi concebida para ser aplicada na produção do software livre (e para programadores que trabalham sobre códigos), mas não é tão adequada à produção artística, que tem outra dinâmica. Por exemplo, a GPL permite que as obras derivadas tenham destinação comercial, sem necessariamente reverter em remuneração financeira para o criador da obra original. O importante é que o código-fonte permaneça aberto. Para os programadores isso pode ser interessante, já que sua lógica de retribuição é outra: o sucesso de seus programas pode lhe render grande reputação no meio, destacando-o na comunidade, e gerar oportunidades de trabalho na forma de prestação de serviço. $\mathrm{O}$ mesmo não acontece, no entanto, com a produção artística. Ao publicar um livro, por exemplo, e liberar cópias para uso comercial, corre-se o risco de ter a obra apropriada por uma editora privada, sem nenhuma contrapartida para o autor.

Uma das iniciativas com o objetivo de aproximar o conceito copyleft da criação artística é a Licença Arte Livre (Licence Art Libre). A proposta concebida pelo grupo francês Copyleft Attitude em 2000 incentiva a ampla circulação dos bens intelectuais, permitindo o compartilhamento e a transformação das obras a fim de intensificar as possibilidades de criação com ênfase na preservação do patrimônio comum, tendo como princípios a liberdade para usar, copiar, compartilhar, transformar, e a proibição da apropriação exclusiva ${ }^{4}$.

Existem ainda outras licenças lançadas com o objetivo de atender a um espectro mais amplo de áreas produtivas, oferecendo também alternativa às restriçóes da propriedade intelectual, mas com especial atenção ao fortalecimento do bem comum. São as licenças chamadas copyfarleft $t^{5}$, que estabelecem regras diferentes para aqueles inseridos na produção coletiva e colaborativa e para os agentes privados. Um exemplo é a Peer Production License ${ }^{6}$, na qual apenas pessoas envolvidas em projetos colaborativos, cooperativas e entidades sem fins lucrativos podem compartilhar e adaptar a produção, até mesmo para uso comercial, devendo manter a mesma licença em todas as obras derivadas. No entanto, essas permissóes são vedadas a entidades comerciais privadas.

Como vimos, a primeira concepção de licença alternativa proposta por Stallman abriu a possibilidade de um questionamento prático das leis de direito autoral. Muitas outras licenças têm sido criadas desde então, como uma tentativa de adaptação aos novos tempos de produção colaborativa com ampla circulação de bens imateriais. Algumas dessas propostas talvez não tenham ainda aplicação suficientemente disseminada, mas contribuem para trazer à reflexão os temas do fazer coletivo, os parâmetros para sua circulação e a valorização do bem comum. Em diferentes formatos e especificaçôes, os licenciamentos alternativos oferecem uma ampla gama de opções à disposição dos mais variados projetos nos quais se queira definir o tratamento da gestáo de direitos de bens intelectuais para além da legislação vigente. Por isso mesmo, têm sido empregados em várias áreas de produção, desde softwares e obras artísticas, até publicações editoriais e pesquisas científicas ${ }^{7}$. 


\section{Considerações finais}

Ao analisarmos a historicidade das noçóes de autoria e de propriedade intelectual, podemos perceber os desafios que enfrentamos na atualidade, já que os parâmetros que estabeleceram essas noçôes nos séculos XVIII e XIX não dão mais conta das dinâmicas produtivas do século XXI. Vivemos, portanto, num impasse em que os marcos regulatórios relativos à gestão de bens intelectuais em vigor vão de encontro às práticas de criação compartilhada amplamente disseminadas pelas redes, na qual conteúdos culturais já existentes podem ser apropriados para a produção de novas obras.

Enquanto a sociedade não chega a um consenso sobre a revisão da legislação vigente, ativistas de diversas áreas, como programadores e artistas, estão propondo soluções práticas através de licenças alternativas que materializam uma nova visão de autoria e de gerenciamento de direitos de obras intelectuais, que vão além da concepção que toma o indivíduo como elemento central do processo criativo. Com diferentes visóes políticas - mais liberais, como o Creative Commons; ou mais à esquerda, como os modelos copyfarleft - tais licenciamentos estão viabilizando a existência de novos modelos de produção autoral através das redes eletrônicas, na medida em que garantem a ampla circulação de dados necessária à sua reprodução. Mais ainda, demonstram concretamente a possibilidade de adoção de outros parâmetros para a regulação da circulação dos bens intelectuais, valorizando o interesse coletivo e relativizando o individual, ao preconizar critérios para o fortalecimento do bem comum.

\section{Referências bibliográficas}

BARTHES, Roland. A morte do autor. In: O rumor da língua. $2^{\mathrm{a}}$ ed. Tradução Mario Laranjeira. São Paulo: Martins Fontes, 2004, p. 57-64.

BENNETT, Andrew. The author. New York: Routledge, 2005.

BURKE, Sean. Reconstructing the author. In: Authorship: from Plato to the postmodern. Edinburgh: Edinburgh University Press, 1995, xv-xxx.

FOUCAULT, Michel. O que é um autor?. 6ª ed. Tradução António Fernando Cascais e Eduardo Cordeiro. Lisboa: Passagens, 2006.

FERNANDES, Noélia M. A autoria e o hipertexto. Coimbra: Minerva. 2003. LIANG, Lawrence. A brief history of the Internet from the 15th to the 18th century. In: LOVINK, Geert; TKACZ, Nathaniel (Ed.). Critical point of view - A Wikipedia reader. Amsterdam: Institute of Network Cultures, 2011, p. 50-62.

WOODMANSEE, Martha. The author, art, and the market-Rereading the History of aesthetics. New York: Columbia University, 1994. 


\section{Notas}

1. Dados relativos a abril de 2013 .

2. A tradução é nossa: "each individual has his own thought processes, his own way of forming concepts and connecting them. [...] All that we think we must think according to the analogy of our other habits of thought; and solely through reworking new thoughts after the analogy of our habitual thought processes do we make them our own. [...]Hence, each writer must give his thoughts a certain form, and he can give them no other form than his own because he has no other. But neither can he be willing to hand over this form in making his thoughts public, for no one can appropriate his thoughts without thereby altering their form. This latter thus remains forever his exclusive property".

3. Para uma crítica da licença Creative Commons, cf CRAMER, Florian. "O malentendido do Creative Commons". In: TARIN, Bruno; BELISÁRIO, Adriano (Org.) Copyfight - Pirataria e Cultura Livre. RJ: Azougue, 2012, pp. 177-185.

4. Uma versão da Licença Arte Livre em português pode ser encontrada aqui http:// artlibre.org/licence/lal/pt . Acesso em: 29 abr. 2013.

5. Sobre licenças copyfarleft, conferir KLEINER, Dmytri. "Copyfarleft e Copyjustright”. In: TARIN, Bruno; BELISÁRIO, Adriano (Org.) Copyfight Pirataria e Cultura Livre. Rio de Janeiro: Azougue, 2012, p. 167-176.

6. Uma cópia desta licença se encontra disponível em: <http://p2pfoundation.net/ Peer_Production_License>. Acesso em: 29 abr. 2013.

7. O projeto Synaptic Leap, que pesquisa doenças tropicais negligenciadas, registra seus dados sob a licença Creative Commons Attribution 2.5 (que permite compartilhar, remixar, comercializar, mas sempre com a atribuição de autoria), o que mostra a utilidade deste tipo de licença também para a área científica. Mais informações em <http://www.thesynapticleap.org/>. Acesso em: 29 abr. 2013 